\title{
Gastric polyps: analysis of endoscopic and histological features in our center
}

\author{
F. J García-Alonso, R. M. Martín-Mateos, J. A. González-Martín, J. R. Foruny, E. Vázquez-Sequeiros \\ and D. M. Boixeda de Miquel
}

Department of Gastroenterology. Hospital Universitario Ramón y Cajal. Madrid, Spain

\begin{abstract}
Background and objective: the prevalence of gastric polyps in esophagogastroduodenoscopies (EGDs) ranges between 0.33 and $6.35 \%$. The relative frequency of histological subspecies varies widely among published series. The objective is to describe the endoscopic and histological characteristics of the polypoid lesions, and to study possible associations.

Material and methods: we retrospectively revised the EGDs done in our center in 2009. Demographic, endoscopic and histological data were gathered. We proceeded to a descriptive analysis and studied possible associations.

Results: gastric polypoid lesions were found in 269 of the 6307 (4.2\%) reviewed EGDs, $61 \%$ were found in women. Mean age was 64.93 years (SD: \pm 15.23 ). A single polyp was found in 186 patients (69.1\%), over 10 lesions appeared in 31 (11.5\%). An estimated size of $\leq 3 \mathrm{~mm}$ was found in 108 lesions (37.2\%) and greater than 10 $\mathrm{mm}$ in 52 cases (17.9\%). Most lesions were sessile (90.8\%). The location of $34.8 \%$ was the gastric antrum, $39.3 \%$ were found in the gastric body and $25.9 \%$ were in the fundus. Chronic gastritis was confirmed in $53.5 \%$ of the patients and $46.5 \%$ had received PPIs. Histopathological diagnosis was: hyperplastic polyps $50.9 \%$, fundic gland polyps $7.4 \%$, adenomas 3\%, adenocarcinomas $1.9 \%$ and normal mucosa $29.7 \%$. We found no significant association between the histopathological type of lesions and the use of proton pump inhibitor.

Conclusions: we found polypoid lesions in $4.2 \%$ of the EGDs. The most frequent histopathological findings were hyperplastic polyps (50.9\%), followed by fundic gland polyps (7.4\%), adenomas (3\%), and adenocarcinomas (1.9\%).
\end{abstract}

Key words: Polyps. Gastric mucosa. Proton pump inhibitors.

Received: 10-02-11.

Accepted: 08-04-11.

Correspondence: Francisco Javier García Alonso. Department of Gastroenterology. Hospital Universitario Ramón y Cajal. Ctra. Colmenar Viejo, km. 9.100. 28049 Madrid, Spain.

e-mail: fj.garcia.alonso@gmail.com
García-Alonso FJ, Martín-Mateos RM, González-Martín JA, Foruny JR, Vázquez-Sequeiros E, Boixeda de Miquel DM. Gastric polyps: analysis of endoscopic and histological features in our center. Rev Esp Enferm Dig 2011; 103: 416-420.

\section{INTRODUCTION}

The incidental finding of gastric polyps during the course of a routine endoscopy is an increasingly common fact (1). It has been estimated that these types of polyps appear in $0.33-6.35 \%$ of esophagogastroduodenoscopies (EGDs) (2).

Gastric polyps classification is based on its histological features, and based on that, we can differentiate two important groups: neoplastic and benign polyps. The second group is the most common (3), and among them we may find several subtypes such as hyperplastic or fundic glands polyps. The prevalence of each of these subgroups widely varies depending on the population studied.

There are no specific symptoms related to the presence of gastric polyps. Although more frequently they are asymptomatic, sometimes they may present with gastrointestinal bleeding, anemia or delayed gastric emptying (4).

Gastric polyps may occur in a number of congenital syndromes such as familial adenomatous polyposis, juvenile polyposis or Peutz-Jeghers syndrome, but more often we find them sporadically, constituting an incidental finding.

The aim of our study was to describe the endoscopic and histological features of gastric polyps found in our patient-population. The secondary aim of the study was to assess the relationship between the use of proton pump inhibitors (PPIs) and the presence of fundic glands polyps on EGDs. 
Table I. Demographics and morphological characteristics

\begin{tabular}{ll}
\hline Characteristics & \\
\hline Sex: & \\
Female & $61 \%$ \\
Male & $39 \%$ \\
Age (mean) & 64.93 (years) (SD: \pm 15.23$)$ \\
Number & \\
1 & $69.1 \%$ \\
$2-4$ & $15.3 \%$ \\
$5-10$ & $4.1 \%$ \\
$>10$ & \\
Morphology & \\
Sessile & \\
Pediculated & $90.8 \%$ \\
Location & $9.2 \%$ \\
Antrum & \\
Body & \\
Fundus & $34.8 \%$ \\
Size & $39.3 \%$ \\
$<3$ mm & $25.9 \%$ \\
$3-5$ mm & \\
$5-10$ mm & $37.2 \%$ \\
$>10 \mathrm{~mm}$ & $26.9 \%$ \\
\hline & $17.9 \%$ \\
& $17.9 \%$ \\
& \\
\hline &
\end{tabular}

\section{PATIENTS AND METHODS}

This study was designed as a retrospective analysis of upper gastrointestinal endoscopies (EGDs) performed at Ramón y Cajal Hospital, Madrid, between January 1 and December 31, 2009. For this purpose, all endoscopy reports of explorations carried out during this period of time were reviewed. We included both scheduled endoscopies and emergency procedures. We only excluded from analysis those patients who had been previously included in the study.

Data were obtained from endoscopy reports, electronic medical records (contained on "CAJAL computer database") and, in some cases, by telephone interview. The following information was collected: age, sex, number of gastric polyps found, morphology, size and location. Polyp size was estimated by comparing with the size of biopsy forceps in those polyps that were just biopsied or according to the size reported on the pathologist's report after endoscopic polypectomy. Histologic features, presence of associated chronic gastritis and infection by H. pylori were collected from pathology reports consulted in electronic medical records. The prior use of PPI was established through medical records and, in some cases, where this information was not clearly stated, telephone interviews were conducted. We defined prior use of PPI when it was prescribed for more than 3 months. The protocol was approved by the Clinical Research Ethics Committee (CREC) of our Hospital.

Statistical analysis was performed with the SPSS program (version 15.0). Continuous variables were described

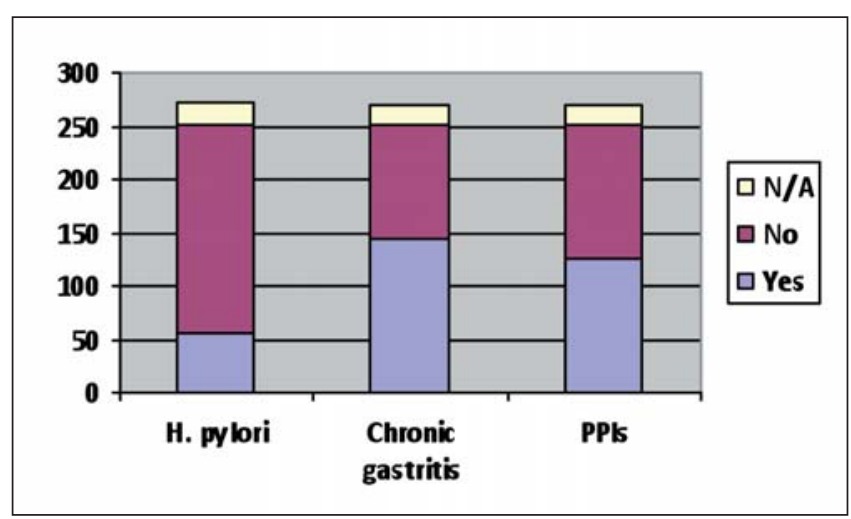

Fig. 1. Percentage of features related to polyp characteristics.

using mean and standard deviation (SD), discrete ones using percentages. The significance of possible associations between discrete variables was evaluated by $\mathrm{c}^{2}$ test of Pearson.

\section{RESULTS}

Six thousand three hundred and seven endoscopies were analyzed, identifying 269 images suggestive of polyps $(4.2 \%)$.

Sixty-one percent of polyps were found in women, and the remaining 39\% in men. Mean age was 64.93 years (SD: \pm 15.23 ).

Regarding the number of polyps found in each patient, 186 cases $(69.1 \%)$ presented a single polyp, $15.3 \%$ of patients, presented 2-4 polyps, $4.1 \%$ had 5 to 10 polyps and $11.5 \%$, had more than 10 polyps.

Most polyps were sessile (90.8\%), and only $9.2 \%$ were pedunculated. A total of $34.8 \%$ were located in the antrum, $39.3 \%$ in the body and $25.9 \%$ in the fundus of the stomach. Regarding size, it was estimated a size $<3 \mathrm{~mm}$ in 108 lesions (37.2\%), and larger than $10 \mathrm{~mm}$ in $52(17.9 \%)$. The rest, $26.9 \%$ and $17.9 \%$ were described with an approximate size of 3-5 and 5-10 mm, respectively (Table I).

Besides the polyp related features, other issues were also evaluated. $H$. pylori infection was diagnosed in $20.8 \%$ of patients, in $72.1 \%$ no bacilli were found in the histological samples and in $7.1 \%$ of cases infection was not investigated.

The chronic use of PPIs was observed in $46.5 \%$ of patients, while $46.8 \%$, reported no use of PPIs. Definitive data could not be obtained in $6.7 \%$ of cases. Chronic gastritis was histologically demonstrated in $53.5 \%$ of patients, in $39.8 \%$ of samples, histology was not consistent with gastritis, and this information could not be answered from reports in $6.7 \%$ of cases (Fig. 1).

Histologically, 50.9\% of polyps were hyperplastic, $7.4 \%$ were fundic gland polyps, $3 \%$ were adenoma and $1.9 \%$ adenocarcinoma. In the remaining $4.8 \%$, lipomas, GIST, xanthomas and inflammatory pseudopolyps were found (Fig. 


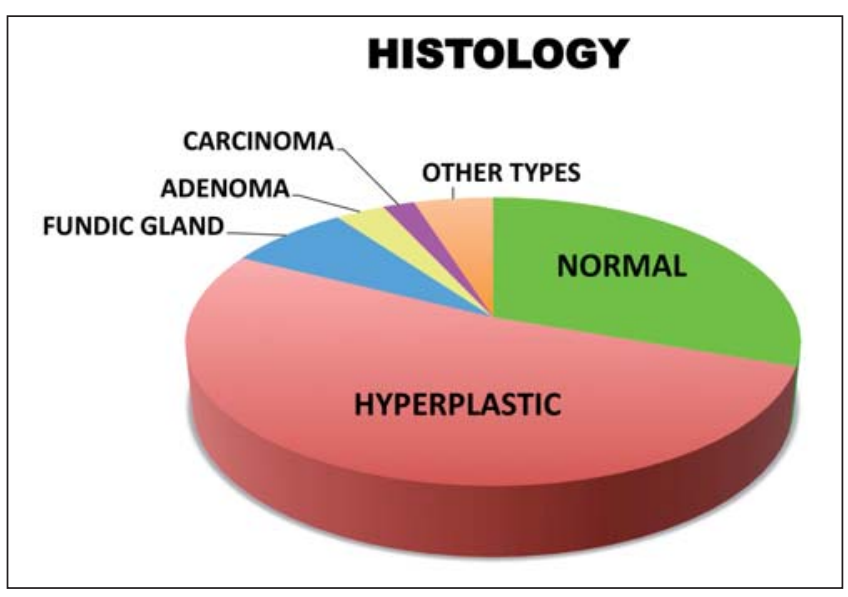

Fig. 2. Percentage of histological subtypes.

2). In 80 patients (29.7\%) gastric specimens identified endoscopically as polyps were described as normal gastric mucosa.

We evaluated the potential association between fundic gland polyps and long-term treatment with PPIs. Among 20 patients with fundic gland polyps, PPI intake could only be investigated in 19 of them; $57.9 \%$ of them reported previous treatment, while in non fundic gland polyps chronic use of PPI was evidenced in $49.1 \%$, a difference not statistically significant $(\mathrm{p}=0.463)$

\section{DISCUSSION}

The body of literature on gastric polyps shows wide variations regarding the prevalence of different histological subtypes.

The largest series of EGDs to date was published by Carmack et al. in 2009 (12), including over 120,000 patients and finding lesions labeled as nodules, polyps or masses in $6.35 \%$ of them. Sixteen percent of them did not meet histopathological criteria for any polypoid or neoplastic lesion. Fundic gland polyps were the most frequent diag- nosis, representing $77 \%$ of all gastric polyps. Hyperplastic polyps and foveolar hyperplasia were found in $17 \%$ of patients. Adenoma, carcinoid tumor, pancreatic heterotopia, xanthoma, lipoma, GIST, leiomyoma, inflammatory fibroid polyp and lymphoma were found in less than $1 \%$ of lesions. There was no statistically significant association between H. pylori infection and any histological subtype. Conversely, both fundic gland and hyperplastic polyps were most frequently found in not infected patients.

Over 26,000 EGDs were included in the work by Morais et al. published in 2007 (13). Polyps were found in only $0.6 \%$ of them. Hyperplastic polyps were the most frequent subtype, $71.3 \%$, while fundic gland polyps and adenomas appeared in 16.3 and $12.4 \%$ respectively. Two percent of polyps were adenocarcinomas. Lesions endoscopically suggestive of polyps without histological correlation were not included in the analysis.

A study on pediatric population found polypoid lesions in 45 out of 5,766 EGDs. No histological diagnosis of polypoid or neoplastic lesion was achieved in $11 \%$ of them, $42 \%$ were hyperplastic polyps, $40 \%$ fundic gland polyps and $5 \%$ adenomas.

The relative prevalence of different subtypes found in series with patients from nearer geographical areas resemble our results. The presence of hyperplastic polyps ranges between 44.5 and $68 \%$ of lesions and fundic gland polyps between 9 and $14 \%$ (15-17).

We have found only one single study on Spanish population, including 5,314 EGDs (18). Polypoid lesions were found in $0.33 \%$ of patients but $37.5 \%$ of them did not meet criteria of polyp or neoplastic lesions. Hyperplastic polyps included $46.9 \%$ of specimens, $12.5 \%$ were adenomas and $3.1 \%$ adenocarcinomas.

There is a significant difference in the prevalence of histological subtypes among the published series (Table II). These discrepancies suggest a possible relationship between certain histological kinds and the geographical location of the population included, which may be due to demographic, genetic or socioeconomic characteristics. Further studies are required to disclose these possible associations.

Table II.

\begin{tabular}{|c|c|c|c|c|c|c|c|}
\hline & Country & Year & N. ${ }^{\circ}$ polyp & Hyperplastic & Fundic Gland polyp & Adenoma & Carcinoma \\
\hline Carmack et al. & USA & 2009 & 7949 & $17 \%$ & $77 \%$ & $0.69 \%$ & $1.35 \%$ \\
\hline Morais et al. & Brazil & 2007 & 153 & $71.3 \%$ & $16.3 \%$ & $12.4 \%$ & $2 \%$ \\
\hline Ljubicic et al. & Croatia & 2002 & 42 & $68 \%$ & $9 \%$ & $23 \%$ & NS \\
\hline Gencosmanoglu et al. & Turkey & 2003 & 150 & $64 \%$ & $14 \%$ & $3 \%$ & NS \\
\hline Macenlle et al. & Spain & 2003 & 64 & $46.9 \%$ & $0 \%$ & $12.5 \%$ & $3.1 \%$ \\
\hline Sivelli et al. & Italy & 2002 & 164 & $44.5 \%$ & $0 \%$ & $16.4 \%$ & $0.6 \%$ \\
\hline Attard et al. * & USA & 2002 & 40 & $42 \%$ & $40 \%$ & $2 \%$ & NS \\
\hline García-Alonso, Martín et al. & Spain & 2010 & $269 * *$ & $50.9 \%$ & $7.4 \%$ & $3 \%$ & $1.9 \%$ \\
\hline
\end{tabular}

*Study on pediatric population. **Number of patients. NS: not stated. 
A remarkable $29.7 \%$ of our patients had no evidence of polyp or neoplastic lesion on histological examination. A deeper analysis showed that $43.7 \%$ of these were $<3 \mathrm{~mm}$ $(71.2 \%$ under $5 \mathrm{~mm})$. The proportion of lesions without a significant histological diagnosis is similar to the $37.5 \%$ reported by Macenlle et al. (18) but higher than in the study published by Carmack (16\%) (12). That study reported that $79.1 \%$ of lesions according to their endoscopic appearance were $<5 \mathrm{~mm}$ while the latter offered no size stratified analysis. Data on the proportion of specimens without a significant histological diagnosis is not included on other published series or remains low, as in the pediatric patients by Attard et al. (11\%) (14). Based on these data, one may arrive that smaller lesions have higher chances to lack a histological diagnosis.

In our series, $32.8 \%$ of specimens $<3 \mathrm{~mm}$ displayed no significant histological correlate, while this only appeared on $18.3 \%$ of lesions over $10 \mathrm{~mm}$. Considerable discrepancy in histologic findings between endoscopic forceps biopsies and resected specimens has been published in other series (19).

The association between hyperplastic polyps and $H$. pylori infection is still uncertain, with studies offering data for $(20,21)$ and against it $(12,22)$. There are many potential sources for bias in our study (retrospective study design, PPI at the time of endoscopy in $46.5 \%$ of patients, use of histology as the only method to address the presence of $H$. pylori without further knowledge of the location and number of the biopsies taken) to consider them an appropriate source to study this association.

A relationship between PPIs and fundic gland polyps has not yet been fully established. Jalving et al. published a study including 599 patients, 322 of them on PPI (23). Fundic gland polyps were observed in 107 patients, 75 on PPIs and 32 untreated. A significant association was found only in the subgroup of patients treated for over 1 year. A retrospective study by Vieth offered opposite results. A cohort of 2,251 patients with no H. pylori infection and on PPI for at least 1 week was compared to a control group including 28,096 patients without $H$. pylori infection. No significant association was found, as both groups had a similar prevalence of fundic gland polyps (5.0\% with PPI and $5.2 \%$ without them). Although these papers may suggest a possible association with long term treatment, our data do not support a relationship between PPI and fundic gland polyps. We established that treatments over 3 months were considered as long term treatment with PPI and therefore we cannot exclude that a larger interval might have found a significant association.

In summary, we report a series of over 6,300 EGDs presenting gastric polyps in $4.2 \%$ of them. Hyperplastic polyps were the most frequent $(50.9 \%)$ followed by fundic gland polyps (7.4\%). We found no significant association between PPI intake and any histological kind of polyp.

\section{REFERENCES}

1. Gencosmanoglu R, Sen-Oran E, Kurtkaya-Yapicier O, Avsar E, Sav A, Tozun N. Gastric polypoid lesions: analysis of 150 endoscopic polypectomy specimens from 91 patients. World J Gastroenterol 2003;9:2236-9.

2. Carmack SW, Genta RM, Graham DY, Lauwers GY. Management of gastric polyps: a pathology-based guide for gastroenterologists. Nat Rev Gastroenterol Hepatol 2009;6:331-41.

3. Vallot T. Gastric polyps. Presse Med 2007;36:1412-7.

4. Oberhuber G, Stolte M. Gastric polyps: an update of their pathology and biological significance. Virchows Arch 2000;437:581-90.

5. Stolte M, Bethke B, Seifert E, Armbrecht U, Lütke A, Goldbrunner P, et al. Observation of gastric glandular cysts in the corpus mucosa of the stomach under omeprazol treatment. Z Gastroenterol 1995;33:146-9.

6. Freeman HJ. Proton pump inhibitors and an emerging epidemic of gastric fundic gland polyposis. World J Gastroenterol 2008;14:1318-20.

7. Abraham SC, Singh VK, Yardley JH, Wu TT. Hyperplastic polyps of the stomach: associations with histologic patterns of gastritis and gastric atrophy. Am J Surg Pathol 2001;25:500-7.

8. Daibo M, Itabashi M, Hirota T. Malignant transformation of gastric hyperplastic polyps. Am J Gastroenterol 1987;82:1016-25.

9. Davaris P, Petraki K, Archimandritis A, Haritopoulos N, Papacharalampous N. Mucosal hyperplastic polyps of the stomach. Do they have any potential to malignancy? Pathol Res Pract 1986;181:385-9.

10. Orlowska J, Jarosz D, Pachlewski J, Butruk E. Malignant transformation of benign epithelial gastric polyps. Am J Gastroenterol 1995;90:2152-9.

11. Nakamura T, Nakano G. Histopathological classification and malignant change in gastric polyps. J Clin Pathol 1985;38:754-64.

12. Carmack SW, Genta RM, Schuler CM, Saboorian MH. The current spectrum of gastric polyps: a 1 year national study of over 120.000 patients. Am J Gastroenterol 2009;104:1524-32.

13. Morais DJ, Yamanaka A, Zeitune JM, Andreollo NA. Gastric polyps: a retrospective analysis of 26,000 digestive endoscopies. Arq Gastroenterol. 2007;44:14-7.

14. Attard TM, Yardley JH, Cuffari C. Gastric polyps in pediatrics: an 18year hospital-based analysis. Am J Gastroenterol 2002;97:298-301.

15. Sivelli R, Del Rio P, Bonati L, Sianesi M. Gastric polyps: a clinical contribution. Chir Ital 2002;54:37-40.

16. Ljubici N, Kujundzi M, Roi G, Bani M, Cupi H, Doko M, et al. Benign epithelial gastric polyps -frequency, location, and age and sex distribution. Coll Antropol 2002;26:55-60.

17. Gencosmanoglu R, Sen-Oran E, Kurtkaya-Yapicier O, Avsar E, Sav A, Nurdan T. Gastric polypoid lesions: Analysis of 150 endoscopic polypectomy specimens from 91 patients. World J Gastroenterol 2003;9:2236-9.

18. Macenlle García R, Bassante Flores LA, Fernández Seara J. Pólipos gástricos epiteliales. Estudio retrospectivo 1995-2000. Rev Clin Esp 2003;203:368-72.

19. Yoon WJ, Lee DH, Jung YJ, Jeong JB, Kim JW, Kim BG, et al. Histologic characteristics of gastric polyps in Korea: emphasis on discrepancy between endoscopic forceps biopsy and endoscopic mucosal resection specimen. World J Gastroenterol 2006;12:4029-32.

20. Ljubicic N, Banic M, Kujundzic M, Antic Z, Vrkljan M, Kovacevic I, et al. The effect of eradicating Helicobacter pylori infection on the course of adenomatous and hyperplasic gastric polyps. Eur J Gastroenterol Hepatol 1999;11:727-30.

21. Ohkusa T, Takashimizu I, Fujiki K, Suzuki S, Shimoi K, Horiuchi T, et al. Disappearance of hyperplasic polyps in the stomach after eradication of Helicobacter pylori: a randomized controlled trial. Ann Intern Med 1998;129:712-5.

22. Abraham SC, Singh VK, Yardley JH. Hyperplastic polyps of the stomach. Associations with histological patterns of gastritis and gastric atrophy. Am J Surg Pathol 2001;25;500-7.

23. Jalving M, Koornstra JJ, Wesseling J, Boezen HM, De Jong S, Kleibeuker $\mathrm{JH}$. Increased risk of fundic gland polyps during long-term proton pump inhibitor therapy. Aliment Pharmacol Ther 2006; 24:1341-8.

24. Vieth M, Stolte M. Fundic gland polyps are not induced by proton pump inhibitor therapy. Am J Clin Pathol 2001;116:716-20. 